Endurance training

\title{
Endurance in young athletes: it can be trained
}

\section{A D G Baxter-Jones, N Maffulli}

\section{Endurance exercise training enhances exercise tolerance and ultimately improves the performance of young athletes}

\begin{abstract}
A large number of young athletes train for competitive sport before puberty, yet the understanding of their capabilities to benefit from endurance training is limited. ${ }^{12}$ Many studies of endurance trainability of children have methodological flaws. Most investigations that have involved adequate intensity, type, and duration of training have shown in children the qualitative changes expected from adults, although children may need a greater exercise intensity than adults to trigger cardiovascular adaptations to training.
\end{abstract}

\section{PHYSIOLOGY OF ENDURANCE EXERCISE}

Maximal oxygen uptake ( $\left.\mathrm{VO}_{2} \mathrm{MAX}\right)$ is the key cardiorespiratory determinant of endurance exercise. Not all children and adolescents fulfil the adult criteria of obtaining $\mathrm{VO}_{2} \operatorname{MAx}$ by reaching a plateau in oxygen consumption $\left(\mathrm{VO}_{2}\right)$. Peak $\mathrm{VO}_{2^{\prime}}$ the highest level of $\mathrm{VO}_{2}$ elicited during an exercise test to exhaustion, is considered a more appropriate index for determining the endurance exercise potential in children. ${ }^{12}$

Another critical variable for endurance performance is anaerobic threshold (AT). In its original concept, AT described the specific level of work below which metabolic acidosis and the associated changes in gas exchange occurred. However, blood lactate levels probably reflect the balance between lactate production and elimination rather than the onset of cellular anaerobiosis. The identification of the threshold point has been circumvented by the use of fixed blood lactate reference levels, although it should be acknowledged that the specific theoretical underpinning of the use of the 4.0 $\mathrm{mM}$ level in adults is quite different from that of the classical $\mathrm{AT}^{3}$ As children can exercise close to exhaustion without exceeding a blood lactate of $4.0 \mathrm{mmol} / \mathrm{l}$, an alternative $2.5 \mathrm{mmol} / \mathrm{l}$ level is considered more appropriate. ${ }^{3}$ The cut off age for when this level is applicable in children is uncertain.

Peak $\mathrm{VO}_{2}$ and $\mathrm{AT}$ are major determinants of endurance exercise performance. An increase in either variable improves the athlete's ability to sustain a higher rate of aerobic energy expenditure. Absolute peak $\mathrm{Vo}_{2}$ (litres/min) increases with age in both boys and girls, although the increase in girls is somewhat less, particularly after puberty. ${ }^{4}$

\section{EFFECTS OF GROWTH ON ENDURANCE}

Performance in endurance sports (running, swimming, cycling, rowing, etc) improves steadily throughout childhood. ${ }^{6}$ Genetic makeup seems to play a prominent role in children's endurance capabilities and response to training, and the effects of training may be small. ${ }^{7}$

\section{SCALING ISSUES}

As body size significantly affects the measurement of physiological performance, $\mathrm{VO}_{2}$ should be normalised or scaled to account for the differences in body size. When $\mathrm{VO}_{2}$ is expressed as $\mathrm{ml} / \mathrm{kg} / \mathrm{min}$ (indicating that changes in $\mathrm{VO}_{2}$ are in direct proportion to changes in body mass), sex differences become evident. Generally, relative peak $\mathrm{VO}_{2}(\mathrm{ml} / \mathrm{kg} / \mathrm{min})$ remains stable throughout childhood and adolescence in boys, and decreases progressively in girls. ${ }^{36}$

Scaling peak $\mathrm{VO}_{2}$ using a "per body mass" ratio standard, however, is theoretically limited. Some authors have expressed peak $\mathrm{VO}_{2}$ relative to mass. ${ }^{37} \mathrm{How}-$ ever, growth in children is not a regular process, and differential or non-isometric changes occur in the proportions of body segments. Therefore this theoretical exponent may not be appropriate for all age groups. ${ }^{3}$ With a log-linear scaling method, peak $\mathrm{VO}_{2}$ increases throughout childhood to puberty in both boys and girls. After puberty, peak $\mathrm{VO}_{2}$ continues to increase in boys, and it levels in girls as they approach adulthood, ${ }^{3}$ probably a consequence of the increase in subcutaneous fat in girls. ${ }^{4}$ Endurance capabilities of children improve as they become older and increase in body size. This improvement differs slightly in boys and girls, as girls increase their capabilities in a similar way to boys, but with less magnitude. ${ }^{3}$

\section{EFFECTS OF TRAINING ON AEROBIC POWER}

The rate and magnitude of increases in peak $\mathrm{VO}_{2}$ resulting from training in adults is related to baseline measurements of $\mathrm{VO}_{2} \mathrm{MAX}$ and the frequency, duration, and intensity of the exercise regimen. Young adults typically show a $15-20 \%$ increase in $\mathrm{VO}_{2} \mathrm{MAX}$ with training, although there may be large intrasubject variation due to genetic factors. ${ }^{7}$

Compared with adults, there are fewer reports on the response of children to exercise training. Early research suggested that aerobic training did not influence levels of peak $\mathrm{VO}_{2}$ before puberty. ${ }^{8}$ One explanation for the lack of trainability in children was that they have greater levels of habitual physical activity, which maintains them closer to their $\mathrm{VO}_{2} \mathrm{MAX}$ potential. Another explanation was that the habitual physical activity that children undertake, although plentiful, is seldom of the duration and intensity believed necessary to improve peak $\mathrm{VO}_{2}$.

\section{PUBERTAL STATUS}

Some authors have stated that there is limited evidence to suggest that training during prepubescence increases peak $\mathrm{VO}_{2}$ beyond the increases attributed to growth. Conversely, others have concluded that peak $\mathrm{VO}_{2}$ responds positively to endurance training in prepubescent children. Two hypotheses have been presented to explain the contentious relationship of maturation to children's aerobic power, ${ }^{36}$ namely that a maturational threshold exists before which children are unable to elicit physiological changes in response to training, or that adolescence is a critical period during which children are particularly susceptible to aerobic training. For example, training initiated one year before the period of rapid growth during puberty induced remarkable increases in peak $\mathrm{Vo}_{2}$, a possible consequence of genetic, environmental, and endocrinological factors. ${ }^{5}$ In a study on the effects of aerobic training on 12 pairs of identical twins (ages 10, 13, and 16 years), the 10 and 16 year old twins improved peak $\mathrm{VO}_{2}$ with training, but the 13 year old twins did not.' Despite the arguments and research suggesting that prepubescent children are not capable of improving their endurance performance with training, ${ }^{10}$ there is much evidence to suggest otherwise. ${ }^{11}$

Although some disagreement remains as to whether aerobic training in prepubescent children causes an improvement in peak $\mathrm{VO}_{2},{ }^{12}$ most studies conclude that such an effect does exist. ${ }^{11}$

Few studies have investigated the relation between peak $\mathrm{VO}_{2}$ and sexual maturity. ${ }^{56}{ }^{14}$ Relative peak $\mathrm{VO}_{2}$ remains steady in boys from maturational ages -6 to +2 maturity years (where 0 years represents peak height velocity), with a

Abbreviations: $\mathrm{VO}_{2} \mathrm{MAX}$, maximal oxygen uptake; AT, anaerobic threshold 
slight declining trend from -1 to +2 maturity years. In girls, relative peak $\mathrm{VO}_{2}$ shows a progressive decline from -3 to +2 maturity years. ${ }^{5}$ Most studies showed that training increased the endurance capability of postpubescent girls. ${ }^{13} \mathrm{~A}$ recent investigation using multilevel modelling showed that, over the age range 11-18 years, both chronological age and stage of maturity are explanatory variables of peak $\mathrm{Vo}_{2}$, independent of body size and fatness. The increase in peak $\mathrm{VO}_{2}$ is common to both boys and girls, but there is a progressive divergence in values in favour of boys. ${ }^{14}$

Young athletes who begin to train seriously have pronounced functional advantages, but this finding may actually be related to other research showing that young athletes who regularly train in endurance sports, in general, have early sexual maturation. ${ }^{15}$ In other words, the athletes who begin training young and experience success may actually do so because they are more physiologically mature than their chronologically age matched peers.

Sensitivity to aerobic training is largely dependent on genotype: only about $30 \%$ of peak $\mathrm{VO}_{2}$ can be accounted for by training itself. Individuals who possess high aerobic power are likely to select themselves for participation in endurance sports. ${ }^{16}$

\section{DEVELOPMENT OF AT}

In general, blood lactate levels are lower in children and adolescents than adults at any given exercise intensity. ${ }^{3}$ Although this may be due to differences in hormone and muscle metabolism, faster oxygen transients, or levels of increased habitual physical activity, there are insufficient data to confirm these explanations. Theoretical problems with standardisation of lactate criteria have hindered the understanding of AT determination in children. ${ }^{3}$
When ventilatory measures have been used to measure AT, larger increases have been observed in the training group than the control group. Thus it is likely that top performing endurance child athletes, at given absolute exercise intensities, have lower lactate levels which are cleared more rapidly than in less fit children of the same sex, age, and maturational level..$^{1-3}$

\section{CONCLUSION}

Endurance exercise training enhances exercise tolerance and ultimately improves the performance of young athletes. The two major physiological variables thought to determine endurance performance are $\mathrm{VO}_{2} \mathrm{MAX}$ and AT. Peak $\mathrm{VO}_{2}$ has been widely studied in young athletic and non-athletic populations, and has remained remarkably consistent over the last 50 years, an indication of its close association with growth. The relatively few studies that have investigated the effects of exercise programmes in young athletes have shown increases in peak $\mathrm{VO}_{2}$ with training. However, the change is smaller than that observed in adults. ${ }^{17}$ Although the effects of exercise training on prepubescent children remains debatable, ${ }^{18}$ appropriate endurance training in children and adolescents does improve peak $\mathrm{VO}_{2}$ and AT.

Br J Sports Med 2003;37:96-97

\section{Authors' affiliations}

A D G Baxter-Jones, College of Kinesiology, University of Saskatchewan, Saskatoon, SK, Canada

N Maffulli, Department of Trauma and Orthopaedic Surgery, Keele University School of Medicine, Stoke on Trent, Staffordshire UK

Correspondence to: Professor Maffulli, Department of Trauma and Orthopaedic surgery, Keele University School of Medicine, North Staffordshire Hospital, Thornburrow Drive, Hartshill, Stoke on Trent, Staffordshire ST4 7QB, UK; osa 14@keele.ac.uk

\section{REFERENCES}

1 Armstrong N, Welsman JR. Aerobic fitness In: Armstrong N, van Mechelen W, eds. Paediatric exercise science and medicine. Oxford: Oxford University Press, 2000:65-74.

2 Armstrong N, Welsman JR. Aerobic fitness. In: Armstrong N, van Mechelen W, eds. Paediatric exercise science and medicine. Oxford: Oxford University Press, 2000: 173-82.

3 Armstrong N, Welsman JR. Assessment and interpretation of aerobic fitness in children and adolescents. Exerc Sport Sci Rev 1994;22:435-76.

4 Kemper HCG, Verschuur R. Growth, health and fitness of teenagers. Basel: Karger, 1985:107-26.

5 Mirwald RL, Bailey DA. Maximal aerobic power. London, Ontario: Sports Dynamics, 1986.

6 Baxter-Jones A, Goldstein H, Helms PJ. The development of aerobic power in young athletes. J Appl Physiol 1993;75: 1160-7.

7 Bouchard C, Dionne FT, Simoneau JA, et al. Genetics of aerobic and anaerobic performances. Exerc Sport Sci Rev 1992;20:27-58.

8 Yoshhida T, Ishiko I, Muraoka I. Effect of endurance training on cardiorespiratory functions of 5-year-old children. Int J Sports Med 1980;1:91-4

9 Weber G, Kartodihardjo, Klissouras V. Growth and physical training with respect to heredity. J Appl Physiol 1976;40:211-15.

10 Welsman J, Armstrong N, Withers S. Responses of young girls to two modes of aerobic training. Br J Sports Med 1997;31:139-42.

11 Rowland TW, Boyajian A. Aerobic response to endurance exercise training in children. Pediatrics 1995;96:654-8.

12 Bar-Or O. Pediatric sports medicine for the practitioner. New York: Springer-Verlag, 1983

13 Rowland TW, Varzeas MR, Walsh CA. Aerobic responses to walking training in sedentary adolescents. Journal of Adolescent Health 1991;12:30-4.

14 Armstrong N, Welsman JR. Peak oxygen uptake in relation to growth and maturation in 11 - to 17-year-old humans. Eur J Appl Physiol 2001;85:546-51.

15 Malina RM. Physical growth and biological maturation of young athletes. Exerc Sport Sci maturation of young athlete
$\operatorname{Rev} 1994 ; 22: 389-434$.

16 Baxter-Jones ADG, Helms PJ. Effects of training at a young age: a review of the training of young athletes (TOYA) study. Pediatr Exerc Sci 1996;8:310-27.

17 Pate RR, Ward DS. The child and adolescent athlete. Oxford: Blackwell Science, 1996: 130-7.

18 Rowland TW. Exerciser and children's health. Champaign, IL; Human Kinetics, 1990. 